\section{CRITICAL MEDICAL AND SURGICAL NURSING JOURNAL \\ Vol. 10, No. 1, April 2021}

Journal Homepage: https://e-journal.unair.ac.id/CMSNJ

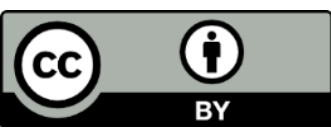

This is an Open Access article distributed under the terms of the Creative Commons Attribution 4.0 International License

\title{
Factors Related to the Level of Health Literacy in Patients with Hypertension: Literature Review
}

\author{
Rezkisa Dwi Prambudia1, Ika Yuni Widyawati ${ }^{\circledR D}$, Eka Mishbahatul Mar'ah Has ${ }^{2}$ (D) \\ ${ }^{1}$ Bachelor Student, Faculty of Nursing, Universitas Airlangga, Surabaya, Indonesia \\ ${ }^{2}$ Faculty of Nursing, Universitas Airlangga, Surabaya, Indonesia
}

\section{ARTICLE HISTORY \\ Received: Jan 13, 2021 \\ Accepted: May 8, 2021 \\ Published: IN PRESS \\ KEYWORDS \\ Age, Health Literacy, Hypertension, Self- \\ Management Efficacy}

\section{CORRESPONDING AUTHOR}

Ika Yuni Widyawati

ika-y-w@fkp.unair.ac.id

Faculty of Nursing,

Universitas Airlangga,

Surabaya, Indonesia

\begin{abstract}
Introduction: Hypertension is the leading cause of death worldwide. People with hypertension often receive health education about their health but cannot implement it. Patients with hypertension must be responsible for self-management related to the level of a person's health literacy, such as efforts that should they take so that the illness they suffer from is not getting worse. The aim of this study is to determine the factors related to the level of health literacy in hypertensive patients.
\end{abstract}

Methods: Search for articles and journals conducted in the last ten years, from 2010-2020 and published on the internet using Scopus, Science Direct, ProQuest, Pubmed, Google Scholar, Portal Garuda, and SINTA by using chosen keyword adjusted to the Medical Subject Heading (MeSH) and Indonesian Thesaurus, namely, "factors", "health literacy", " After analysis and tabulation from some of the articles and journals, there are several factors related to the level of health literacy in hypertensive patients such as, education, age, job, income, knowledge, acculturation, self-management efficacy, HBPM (Home Blood Pressure Measurement), regular use of medicine, systolic blood pressure, health service access, health information access, and social support.

Results: There are several factors related to the level of health literacy in patients with hypertension after analyzing journals or articles .. This study is expected to increase knowledge for nurses about the level of health literacy of hypertensive patients. acculturation, self-management efficacy, HBPM (Home Blood Pressure Measurement), regular use of medicine, systolic blood pressure, health service access, health information access, and social support. Discussion: There are several factors related to the level of health literacy in patients with hypertension after analyzing journals or articles .. This study is expected to increase knowledge for nurses about the level of health literacy of hypertensive patients. acculturation, self-management efficacy, HBPM (Home Blood Pressure Measurement), regular use of medicine, systolic blood pressure, health service access, health information access, and social support.

Conclusion: There are several factors related to the level of health literacy in patients with hypertension after analyzing journals or articles. This study is expected to increase knowledge for nurses about the level of health literacy of hypertensive patients.

Prambudia, R. D., Widyawati, I. K., \& Has, E. M. M. (2021). Factors Related to The Level of Health Literacy in Patients with Hypertension: Literature Review. Crit. Méd. Surgical. Nurs. J, $10(1), x x-x x$.

\section{INTRODUCTION}

Hypertension or high blood pressure is the leading cause of premature death worldwide. Hypertension is a condition in which a person's systolic blood pressure is above $140 \mathrm{mmHg}$ and diastolic blood pressure is above $90 \mathrm{mmHg}$. People with hypertension often receive health education regarding its health but can not apply it where precisely worsening the situation even though as it is known that hypertension is a chronic disease, 
therefore sufferers must be responsible for selfmanagement behavior both to reduce symptoms and reduce the risk of complications where it is related to a person's health literacy level.

Health literacy is a person's ability to access, understand, and the ability to be able to apply the information and health services needed in making the right decisions about health (World Health Organization, 1998). However, there are factors related to the level of health literacy that cause the level of health literacy for each individual to be different. Research that has been conducted by Wang et al. (2017) proved that the low health literacy possessed by hypertensive patients is related to unwillingness to receive regular treatment, the importance of self-management, and non-compliance with medication.

Soemitro (2014) reports that the level of health literacy or the level of health literacy in hypertensive patients at the Malang District Health Center mostly has a poor literacy level that is, $65.35 \%$. Patients with low levels of health literacy will be worse off in managing a chronic disease. This makes health literacy a predictor for one's health.

The factors related to the level of health literacy in sufferers of each disease are likely to be different. This is because the condition of a person's disease also affects. Research conducted by Santosa (2012) where age, education level, access to health information, and income affect a person's health literacy level.

Another study conducted by Nazmi et al (2015) states that ethnicity / race, socioeconomic status, home status, received empathy, happiness and acculturation have significant results to influence health literacy. Broadly speaking, the factors related to the level of health literacy are the level of knowledge, the ability to access health information, the level of education, age, gender, occupation, income, and the ability to access health services.
Overcoming a chronic disease requires self-care management, adherence to taking recommended drugs, as well as diet and lifestyle modifications. This is related to the level of health literacy. Health literacy has an important role in health promotion. This is because health literacy plays a role in community empowerment.

Based on the description above, the author intends to conduct research on what factors are associated with health literacy in patients with hypertension using secondary data that has been available through literature reviews or literature studies. The purpose of this study is to determine related factors with health literacy in patients with hypertension using secondary data.

\section{METHOD}

The literature search was carried out in May-June 2020 using secondary data. The formulation of research questions using PICOT where the population is hypertension sufferers; Interest is a factor related to the level of health literacy, namely knowledge, age, education, occupation, income, access to health information, and access to health services for patients with hypertension; Comparison does not exist; The outcome of the reviewed articles was a factor related to the level of health literacy in patients with hypertension based on empirical studies in the last ten years; and for Time, the articles or journals to be reviewed are research journals conducted in the period 2010-2020. And the keywords used are adjusted to the Medical Subject Heading (MeSH) and Indonesian Thesaurus, namely The articles or journals used were obtained from various databases including, Scopus, Science Direct, ProQuest, Pubmed, Google Scholar, Garuda Portal, and SINTA using selected keywords and those published in the last 10 years, namely in the range of 2010-2020 which can be accessed in full text in pdf and scholarly format (peer reviewed journals). The inclusion criteria in this literature study include articles, patient population with hypertension, level of health literacy, and study 
research articles conducted in the last 10 years, namely 2010-2020. Data analysis and tabulation was carried out in articles or journals to determine eligibility articles or journals in the preparation of this literature study.

\section{RESULT}

It was found 1,173 articles or research journals, then screened 926 articles or journals that were not relevant. Then, as many as 247 articles were evaluated based on their titles and abstracts. Elimination was carried out on articles that did not meet the inclusion criteria where the population was not patients with hypertension as many as 183 articles, 28 articles that were not full text, and 7 articles that used languages other than Indonesian and English so that the number of articles used in this literature review was as many as 7 articles. 10 articles with conditions, namely English articles translated into Indonesian. Factors related to the level of health literacy in hypertensive patients are grouped based on the stage of health literacy.

\section{Access Stage}

At the access stage, factors related to the level of health literacy in hypertensive patients include access to health information and access to health services. The more affordable access to health services will increase the level of health literacy of hypertensive patients (Andrianys et al., 2016). In addition, Andrianys et al. (2016) also stated that easy access to health information will increase the level of health literacy of hypertensive patients.

\section{Understanding Stage}

At the understanding stage, factors related to the level of health literacy in hypertensive patients include age, education, occupation, income, knowledge, selfmanagement efficacy, acculturation, and social support. According to Borges et al. (2019) age is a factor related to inadequate levels of health literacy in adults with hypertension. Sahroni et al. (2019) in their research stated that age is one of the demographic factors related to social health determinants related to health literacy scores. Another study conducted by Andrianys et al. (2016) stated that the older a person is, the lower his health literacy is.

Research which states that education is one of the factors related to the level of health literacy in hypertensive patients is a study conducted by Andrianys et al. (2016) where the higher a person's education level, the higher the level of health literacy they have. Apart from that, another study conducted by Borges et al. (2019) and Ingram and Ivanov (2013) also show the same results where the length of schooling is a factor related to inadequate levels of health literacy in adults with hypertension and someone who is more educated is more literate about health literacy.

Sahroni et al. (2019) in their research shows that education is one of the demographic factors related to social health determinants related to health literacy scores. The results of research conducted by Shi et al. (2017) show that education level is one of the factors that has a significant relationship with health literacy. Patients with higher education are associated with higher levels of health literacy and better treatment adherence (Tavakoly Sany et al., 2020). Wahyuningsih, (2019) in his research stated that education has an effect on the health literacy system.

Someone who works has a better level of health literacy than those who do not work (Andrianys et al., 2016). The same results are also shown from the results of research conducted by Shi et al. (2017) whereafter adjusting potential cofounder's, a person's work status has a significant relationship with the level of health literacy. The potential cofounders referred to include age, waist circumference, body mass index, heart rate, alcohol consumption habits, smoking habits, other diseases such as Diabetes Mellitus.

Income is one of the factors related to the level of health literacy in patients with hypertension. A 
person with a minimum income equivalent to the UMR or more has a good level of health literacy (Andrianys et al., 2016). The results of research conducted by Sahroni et al. (2019) show that income is one of the demographic factors related to social health determinants related to health literacy scores. Another study that also stated the same result was a study conducted by Wang et al. (2017) where income is one of the demographic characteristics that affect health literacy.

Other factors related to the level of health literacy in patients with hypertension are knowledge, self-management efficacy, acculturation, and social support. Knowledge of blood pressure has a relationship with health literacy categories such as accessing, reading, understanding, appraisal, and behavioral intentions (Chajaee et al., 2018). Wang et al. (2017) in their research stated that selfmanagement efficacy has an impact on HRQL (Health Related Quality of Life) and at the same time has a positive relationship with the level of health literacy.

Research conducted by Perez (2015) entitled Acculturation, Health Literacy, and Perception of Disease Hypertension among Hispanic Adults has shown that acculturation including preferences in language use, media, and socio-ethnic relations are significantly associated with health literacy scores. Then, Andrianys et al. (2016) in his research showed that the better the social support obtained, the better the health literacy level of hypertensive patients.

\section{Implementing Stage}

At the application stage, factors related to the level of health literacy in patients with hypertension include HBPM (Home Blood Pressure Measurement), regular drug use, and systolic blood pressure. The results of research conducted by Shi et al. (2017) where after adjusting the potential cofounder's (age, waist circumference, body mass index, heart rate, alcohol consumption habits, smoking habits, other diseases such as Diabetes Mellitus), HBPM (Home Blood Pressure Measurement), routine drug use, and pressure A person's systolic blood less than 140 $\mathrm{mmHg}$ has a significant relationship with the level of health literacy.

\section{DISCUSSION}

Factors related to the level of health literacy in hypertensive patients at the access stage include access to health services and access to health information. At the understanding stage, factors related to the level of health literacy in hypertensive patients include education, age, occupation, income, knowledge, self-management efficacy, acculturation, and social support. And at the application stage, factors include HBPM (Home Blood Pressure Measurement), regular drug use, and systolic blood pressure.

Several studies have had different or inconsistent results. Research that shows different or inconsistent results is a weakness of this literature study. There is a need for further research on the factors associated with the level of health literacy in patients with hypertension. So that there is an update on the factors related to the level of health literacy in hypertensive patients in the future.

\section{Access to Health Services with Health Literacy}

Andrianys et al. (2016) stated that the more affordable access to health services, the better the level of health literacy. Research conducted by Forsyth et al. (2008) stated that access to health services depends on the location of health services, doctor's offices, and hospitals that are close to public transportation stops. Access to health services that is easily accessible will make it easier for someone to get information for their health so that their level of health literacy can increase.

\section{Access Health Information with Health Literacy}

Andrianys et al. (2016) also stated that the easier health information is to be accessed, the better the level of health literacy. Research conducted by Lintang Kristi Purwadi and Ika Krismayani (2016) states that the sources of information accessed by 
pregnant women in Wonosobo District are obtained through asking the closest people, asking health workers, magazines, books, internet, smart phone applications, joining in the forum for discussion and sharing. Health information that is easily accessible will increase a person's knowledge and selfmanagement efficacy where the information will be obtained can be applied in everyday life so that the level of health literacy a person has will increase.

\section{Age with Health Literacy}

Research conducted by Andrianys et al. (2016), Borges et al. (2019), and Sahroni et al. (2019) stated that a person's age has a significant relationship with that person's level of health literacy. This is consistent with research conducted by Ownby et al. (2012) which states that older age is closely related to inadequate levels of health literacy in studies assessing math skills, understanding, reasoning, and abilities.

The older a person is, the more vulnerable he is to inadequate levels of health literacy because it is related to his cognitive abilities where there is a decrease in thinking skills so that it will affect behavior to manage external resources such as a person's understanding of information.

\section{Education with Health Literacy}

The results of research conducted by Andrianys et al. (2016), Borges et al. (2019), Ingram and Ivanov (2013), Sahroni et al. (2019), Shi et al. (2017), Tavakoly Sany et al. (2020), and Wahyuningsih (2019) state that the level of education is related to the level of health literacy of a person with hypertension. This is in line with research conducted by Reading et al. (2019) and Veghari et al. (2012) who showed that usually patients with lower educational qualifications have less knowledge of medical care, are less healthy, and have more difficulties in understanding and reading health care information.

Education is needed in getting the information that can be support one's health. The higher a person's education level, the easier it is to receive information, in this case related to health so that later it can improve the quality of life.

\section{Work with Health Literacy}

A study conducted by Andrianys et al. (2016) and Shi et al. (2017) stated that work has a positive relationship with a person's health literacy level. These results are consistent with other research conducted by Pawlak (2005) where a person's employment status can affect the economic capacity that determines a person in getting health services and obtaining health information sources.

In a work bond, there is generally health insurance that will be provided for workers from the workplace. This will increase a person's chance to get health information and services so that the greater the chance for that person to achieve an adequate level of health literacy.

\section{Income with Health Literacy}

Income has a relationship with a person's health literacy level (Andrianys et al., 2016; Sahroni et al., 2019; Wang et al., 2017). This is in accordance with research conducted by $\mathrm{Ng}$ and Omariba (2014) which states that household income is related to the possibility of a person having an adequate level of health literacy. Income is related to a person's education level because education is related to one's job which has an impact on the economic level and financial ability to deal with unexpected problems such as health problems.

\section{Knowledge with Health Literacy}

In a study conducted by Chajaee et al. (2018) stated that knowledge about blood pressure has a relationship with the level of health literacysomeone. In another study, the level of knowledge did not have a significant difference so that this result may be related to the level of education. A person's level of knowledge will affect his efforts in making prevention against a disease, treatment of a disease, and also in his own care. 


\section{Self-Management Efficacy with Health Literacy}

Wang et al. (2017) in their research stated that selfmanagement efficacy is related to the level of health literacy. These findings provide further support to the investigator's point of view that improved selfmanagement predicts high levels of patients' Health Related Quality of Life (HRQL) as well. Increasing selfmanagement efficacy can help patients to have a healthy lifestyle which will help avoid bad hypertension.

Self-management efficacy focuses on selfconfidence in the ability to perform self-management activities. Self-management activities can be carried out by finding, understanding and applying information about health so that they can make the right decisions for health. This effort is called health literacy, so a person's high self-management efficacy score indicates that the person has confidence in carrying out self-management activites related to health literacy.

\section{Acculturation with Health Literacy}

A study conducted by Perez (2015) shows that acculturation has a relationship with a person's health literacy. These results are consistent with other studies conducted by Koskan et al. (2010) where he stated in his research that when a person's acculturation increases, the person's health literacy level will also increase. Acculturation is meant here regarding language use and social preferences. The increased level of acculturation will increase health literacy so that a person's perception of the disease regarding control and understanding of hypertension will also increase.

\section{Social Support with Health Literacy}

In addition, Andrianys et al. (2016) also stated that social support is positively related to health literacy. People who suffer from a disease tend to feel neglected and often think about their illness in a negative light. This is where the role of social support is needed. In general, people who feel comforted, get the attention, and help they need are more likely to receive and apply the recommended medical advice.

Social support has a very big role in a person's psychological well-being. A person with good social support will be able to accept and try to implement the recommendations given so that the level of health literacy of that person will increase.

\section{HBPM (Home Blood Pressure Measurement),} Regular Use of Medicines, and Systolic Blood Pressure with Health Literacy

Research conducted by Shi et al. (2017) stated that after adjusting the potential cofounder's (age, waist circumference, body mass index, heart rate, alcohol consumption habits, smoking habits, other diseases such as Diabetes Mellitus), HBPM (Home Blood Pressure Measurement), regular drug use, and systolic blood pressure have a relationship with the level of health literacy. Routine blood pressure measurement, regular drug use, and maintaining systolic blood pressure within normal ranges can be forms of self-management activities that can increase a person's self-management efficacy so that the level of health literacy is adequate as the end result.

The limitation of research from the preparation of this literature study is that researchers only analyze research articles or journals without measuring the quality of the articles or journals using the Joanna Briggs Institute (JBI) checklist. As well as results that are inconsistent or different in several research articles or journals because health literacy factors influence each other, besides that hypertension drug consumption habits and lifestyle are also reasons for research results that are inconsistent or different in several articles or journals.

\section{CONCLUSION}

Factors related to the level of health literacy in hypertensive patients include access to health services, access to health information, education, age, occupation, income, knowledge, self-management 
efficacy, acculturation, social support, HBPM (Home

Blood Pressure Measurement), regular drug use, and systolic blood pressure. The advantages of this literature study are that the articles or journals used are the latest journals in the last 10 years so that they have experienced updates and innovations from previous articles or journals. The drawback of this literature study is only analyze articles or research journals without measuring the quality of the articles or journals using The Joanna Briggs Institute (JBI) checklist.

\section{REFERENCE}

Andrianys I, Kadar K, Massi N. Precede-Proceed Education Model To Health Literacy's Patient With Hypertension In Pattingalloang Makassar. 2016: 8.

Research and Development Agency for Health KK. Main Results of Riskesdas 2018. Jakarta: Ministry of Health of the Republic of Indonesia; 2018.

Research and Development Agency for Health KK. Basic Health Research (RISKESDAS) 2013. Jakarta: Ministry of Health of the Republic of Indonesia; 2013.

Borges, Fernanda Moura, da Silva, ARV, Lima, LH de O., de Almeida, PC, Vieira, NFC, Machado, ALG Health Literacy of Adults With And Without Arterial Hypertension. RevBrasEnferm. 2019; 72 (3): 646-53. https://doi.org/10.1590/00347167- 2018-0366

Chajaee F, Pirzadeh A, Hasanzadeh A, Mostafavi F. Relationship Between Health Literacy And Knowledge Among Patients With Hypertension In Isfahan Province, Iran. ElectronPhysician. 2018; $\quad 10 \quad$ (3): 6470. https://doi.org/10.1016/i.maturitas.201 $\underline{7.03,225}$

Darvishpour J, Omidi S, Farmanbar R. The Relationship Between Health Literacy And Hypertension Treatment Control And Follow-Up. Casp JHealth Res. 2016; 2 (1): 1-8. https://doi.org/10.1016/j.maturitas.201 $\underline{7.03,225}$

deAraújo, IMB, Jesus, RAF, Teixeira, M. de L., Cunha, ARS, Santos, FM da S., Miranda, SRF Health Literacy Of Patients With HypertensionAndDiabetesIn A Northern Region Of Portugal. RevEnfermReferência.English ed. 2018; 4 (18): 73-82. https: //doi.org/10.12707/RIV18008

Forsyth A, Krizek K, Schively C, Johnson A, Pennucci A, Miller A. Key Questions: Healthcare Access Version Univ Minn. 2008.

Ingram RR PhD, RN, Ivanov LL PhD, RN. Examining the Association of Health Literacy and Health Behaviors in African American Older Adults: Does Health Literacy Affect Adherence to Anti hypertensive Regimens?.J Gerontol Nurs.2013 Mar;39(3):22-

32.https://doi.org/10.3928/0098913420130201-01

Koskan, A., Friedman, DB, Messias, DKH Health Literacy Among Hispanics: A Systematic Research Review (1992-2008). Ethn Groups. : 13.https: //doi.org/ 10.1891/1540- 4153.8.2.65

Lintang Kristi Purwadi, Ika Krismayani. Information Literacy Skills for Pregnant Women in Preparing for Childbirth in Wonosobo District. J Perpust Science. 2016 Oct 1; 5 (4): 311-20.

Marinda N. Health Literacy Analysis of National Health Insurance Participants at Simpang Kawat Community Health Center Jambi City. J Ilm Univ Batanghari Jambi. 2019 Jan 22; 19 (1): 168. http://doi.org/10.33087/ jiubj.v19i1.583

$\mathrm{Ng} \mathrm{E,} \mathrm{Omariba} \mathrm{DWR.} \mathrm{Immigration,} \mathrm{Generational}$ Status And Health Literacy In Canada. Health Educ J. $2014 \quad$ Nov.; 73 (6): 668-82. https://doi.org/10.1177/001789691351 1809

Nursalam P. Nursing Research Methodology: A Practical Approach. 4th ed. Jakarta: Salemba Medika; 2016.

Ownby, RL, Waldrop-Valverde, D., Taha J. Why Is Health Literacy Related to Health? An Exploration Among US National Assessment of Adult Literacy Participants 40 Years of Age and Older.EducGerontol. 2012 Nov; 38 (11): 776-87. https: //doi.org/10.1080/03601277.201 1.645441

Pawlak R. Economic Considerations Of Health Literacy. Nurs Econ. 2005 Jul 1; 23: 173-80, 147.

Perez A. Acculturation, Health Literacy, and Illness Perceptions of Hypertension among Hispanic Adults. J Transcult Nurs. 2015; 26 (4): 386-94. https: //doi.org/10.1177/104365961452 4785

Reading, SR, Black, MH, Singer, DE, et al. Health Literacy and Awareness of Atrial Fibrillation. J Am Heart Assoc. 2019 Apr; 6 (4).https://doi.org/10.1161/】AHA.116.005 128

Rudolfo G, Restila R, et al. Factors Affecting Health Literacy in Health Care Facilities: Systematic Review. 2015; 1: 8

Sahroni S, Anshari D, Krianto T. Social Determinants of Health Literacy Levels in Hypertension Patients at Puskesmas Kota Cilegon. Faletehan Health J. 2019; 6 (3): $111-$ 7.https://doi.org/10.33746/fhi.v6i3.94

Santosa, K S. Factors Associated with the Level of Poor Patient Health at the Faculty Family Doctor Clinic Medicine, University of Indonesia Kiara, DKI Jakarta in 2012. 2012; 144.

Shi D, Li J, Wang Y, Wang S, Liu K, Shi R, et al. Association BetweenHealth Literacy And Hypertension Management In A Chinese Community: A Retrospective Cohort Study.Intern EmergMed. 2017 Sep; 12 (6): 765-76. https: //doi.org/10.1007/s11739-017-1651-7

Soemitro DH. Analysis of the Level of Health Literacy and Knowledge of Hypertension Patients in 
Malang District Health Center. 2014; 13.

Tavakoly Sany, SB, Behzhad, F., Ferns, G., Peyman, N. Health Providers 'Communication Skills Training Affects Hypertension Outcomes. Med Teach. 2018; 40

(2): 154-63.

https://doi.org/10.1080/0142159X.201 7.1395002

Veghari G, Sedaghat M, Maghsodlo S, Banihashem S, Moharloei P, Angizeh A, et al. Impact of Literacy on the Prevalence, Awareness, Treatment and Control of Hypertension in Iran. JCardiovascThorac Res. 2012; 4 (2): 37. https://doi.org/10.5681/ jcvtr. 2012.009

Wahyuningsih T. Health Literacy Patients with Hypertension In Implementing Dietary Adherence to the Elderly in Tegalrejo, Yogyakarta. Surya Med J Science Nursing and Health Sciences Masy. 2019; $14 \quad(1): \quad 1-6$. https://doi.org/10.32504/sm.v14i1.105

Wang C, Lang J, Xuan L, Li X, Zhang L. The Effect Of Health Literacy And Self-Management Efficacy On The Health-Related Quality of Life of Hypertensive Patients In A Western Rural Area Of China: A Cross-Sectional Study. Int J Equity Health. 2017; 16 (1). https: //doi.org/10.1186/s1 2939017-0551-9

World Health Organization. Health Promotion Glossary. 1998; 36 